\title{
Increasing lipid content from biomass of microalgae to produce biofuels with optimization of nitrogen source
}

\author{
Istikhomah Putri Ayuwaningsih ${ }^{1}$, Melati Ferianita Fachrul $^{1 *}$, and Astri Rinanti ${ }^{1}$ \\ ${ }^{1}$ Universitas Trisakti, Environmental Engineering Departement, Faculty of Landscape Architecture and Environmental Technology, \\ Jakarta, Indonesia
}

\begin{abstract}
The aim of this research is to analyze the effect of urea fertilizer as a nitrogen source to lipid productivity of mixed culture of green microalgae consisting of Monoraphidium sp., Chlorella sorokiniana, and Scenedesmus obliquus as lipid sources. In research, cultures were cultivated in a $1.5 \mathrm{~L}$ glass photobioreactor with batch culture system. The operational conditions of this research were carried out at pH $6.0,27^{\circ} \mathrm{C}$, aeration with air flow $150 \mathrm{~mL} / \mathrm{sec}$, and 2400 lux with vary amount of urea as a source of nitrogen as much (grams) $0.0 ; 0.5 ; 1.0$. The Bligh and Dyer extraction is performed to produce biofuels after harvesting process and to analyze lipid content. Analysis of fatty acids using Gas Chromatography Mass Spectrometry (GCMS) Method, analysis of dry weight using Gravimetric Method, and analysis of cell density using Spectrofotometry Method. This research concludes that with 0.5 grams of urea fertilizer can produce dry weight and total lipid content optimally that were $0.26 \%(\mathrm{w} / \mathrm{w})$ and $36,35 \%(\mathrm{w} / \mathrm{w})$. This research concludes that increasing amount of nitrogen source could be increasing green microalgae biomass but is not for increased lipid content. The high lipid content can be produced by decreasing $50 \%$ nitrogen source.
\end{abstract}

\section{Introduction}

Recently, a scarcity of fossil fuels is a reality that couldn't be avoided. It could be happened due to the use of fossil fuels as an energy source for many transportation capable of reaching more than 50\% compared to using other fuels [1]. The scarcity of fossil fuels is causing its price continues to soar up. The stock of fossil fuels will continue to decrease as a result of the amount of consumption continues to increase so the right solution is by using renewable alternative fuels, such as biodiesel.

In an effort to reduce the price of the product biodiesel is then the required solution for the efficiency of the material, the use of land, as well as the time required in the manufacture of biodiesel, such as using microalgae as a source of raw materials. Biodiesel from microalgae has the greatest potential to replace fossil fuels among renewable energy sources due to microalgae could live almost anywhere that has enough sunlight, water and $\mathrm{CO}_{2}$, also has the chemical composition of the cell consisting of proteins, carbohydrates, and fatty acids [2]. These fatty acid components will be extracted into lipids and converted into biodiesel [3].

Microalgae is the most promising organisms as biodiesel sources for third generation because microalgae has high lipid content, which can exceed 15$75 \%$ (from dry weight), as reported in some species [4$6]$.

\footnotetext{
* Corresponding author: melati@trisakti.ac.id
}

To obtain a high amount of lipids then macronutrient especially nitrogen $(\mathrm{N})$ elements in growth medium must be adjusted. Increased lipids could be done if the microalgae is on the condition of stress. That could occur caused by cell components production rates are low, but oil production remains high. The condition of stress, such as a lack of nitrogen led to hampered cell division, but not slowing oil production [7].

The source of nitrogen (N) commonly used chemicals or inorganic compounds, such as potassium nitrate $\left(\mathrm{KNO}_{3}\right)$ and ammonium nitrate $\left(\mathrm{NH}_{4} \mathrm{NO}_{3}\right)$. However, the acquisition of such materials is quite difficult due to the characteristics of materials that are harmful if abused then is required an alternative source of nitrogen $(\mathrm{N})$ that is easy and inexpensive, such as fertilizer. Some of fertilizers used in the cultivation of microalgae are urea fertilizer $\left(\mathrm{CO}\left(\mathrm{NH}_{2}\right)_{2}\right)$, ZA fertilizer $\left(\left(\mathrm{NH}_{4}\right)_{2} \mathrm{SO}_{4}\right)$, TSP fertilizer, Molasses (Orgami), and Silicate (technical).

Therefore, this study aims to analyze the effect of addition of nitrogen $(\mathrm{N})$ source from fertilizer to lipid production by using mixed culture of green microalgae.

\section{Material and methods}

This research consists of 2 stages, namely preparation stage and main reseach stage. Preparation stage is to prepare consortium of green microalgaes, such as Monoraphidium sp., Chlorella sorokiniana, and Scenedesmus obliquus with its growth medium, 
Provasolli Haematococcus Medium (PHM). The source of nitrogen $(\mathrm{N})$ used in growth medium, Provasolli Haematococcus Medium (PHM) is urea fertlizer $\left(\mathrm{CO}\left(\mathrm{NH}_{2}\right)_{2}\right)$. The original addition of nitrogen $(\mathrm{N})$ sources in Provasolli Haematococcus Medium (PHM) is 1.0 grams [8].

Furthermore, the main research stage begins with cultivation process of consortium of green microalgaes within 20 days, then variation of urea fertilizer (CO $\left.\left(\mathrm{NH}_{2}\right)_{2}\right)$ is added in growth media as nitrogen source as much as 0.0 grams $(0 \%), 0.5$ grams $(50 \%)$, and 1.0 grams $(100 \%)$. The growth of cultivated consortium of green microalgaes were measured by using UV-Vis spectrofotometre at wavelength $680 \mathrm{~nm}$, then the result of the analysis is processed into growth curve.

Extraction of microalgae to produce lipids was performed by Bligh \& Dyer method [9] at extraction temperature $30^{\circ} \mathrm{C}$. The extraction results are left one night apart to separate into several layers. The middle and lower layers are used for lipid analysis and dry weight analysis. Calculation percent weight of total lipid and dry weight using the following formula.

$$
\% \text { Lipid }=\left(\frac{A}{A+B}\right) \times 100 \%
$$

Information:

A : Lipid weight (gr)

B : Biomass weight $(\mathrm{gr})$

$$
\% \text { Dry Weight }=\left(\frac{A}{B}\right) \times 100 \%
$$

Information:

A : Sample weight after heated (gr)

B : Sample weight before heated (gr)

\section{Result and discussion}

Measurements of the growth of consortium of green microalgaes, such as Monoraphidium sp., Chlorella sorokiniana, and Scenedesmus obliquus with variation of urea fertilizer addition as a source of nitrogen (N) on growth medium is carried out from lag phase to the stationary phase, which ended on the $20^{\text {th }}$ day.

From the result of UV-Vis spectrophotometer analysis then obtained growth curve as in Fig 1. On the growth curve it has seen that in the consortium of green microalgaes without addition of urea fertilizer has a shorter lag phase compared with other variations, while experiencing the fastest exponential phase ( $8^{\text {th }}$ day) compared to other variations as well. The exponential phase in the the consortium of green microalgaes with addition of urea fertilizer of $50 \%$ and $100 \%$ (from original) each occurred on the same day ( $9^{\text {th }}$ day).

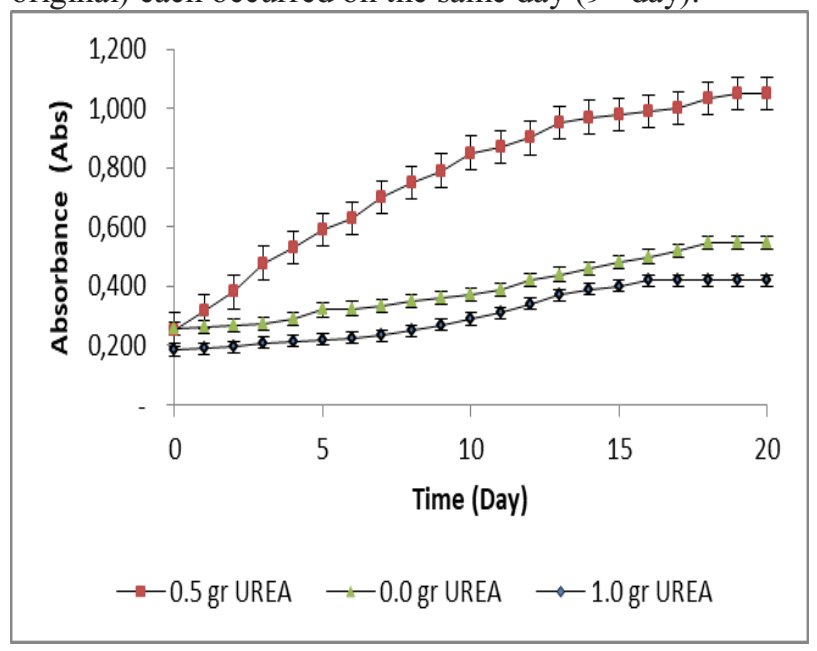

Fig. 1. Growth curve of mixed culture at different urea fertilizer addition.

It could be concluded that the growth of the consortium of green microalgaes will experience optimum and stable growth if there is still nitrogen $(\mathrm{N})$ element in growth medium because microalgae could live optimally if their macronutrient content is fulfilled, as there are elements of C, H, N, P, K, S, Mg, and Ca.

According to the result of the growth curve by using UV-Vis spectrofotometre method in Fig 1. Then analysis of lipid and dry weight is done at exponential phase.

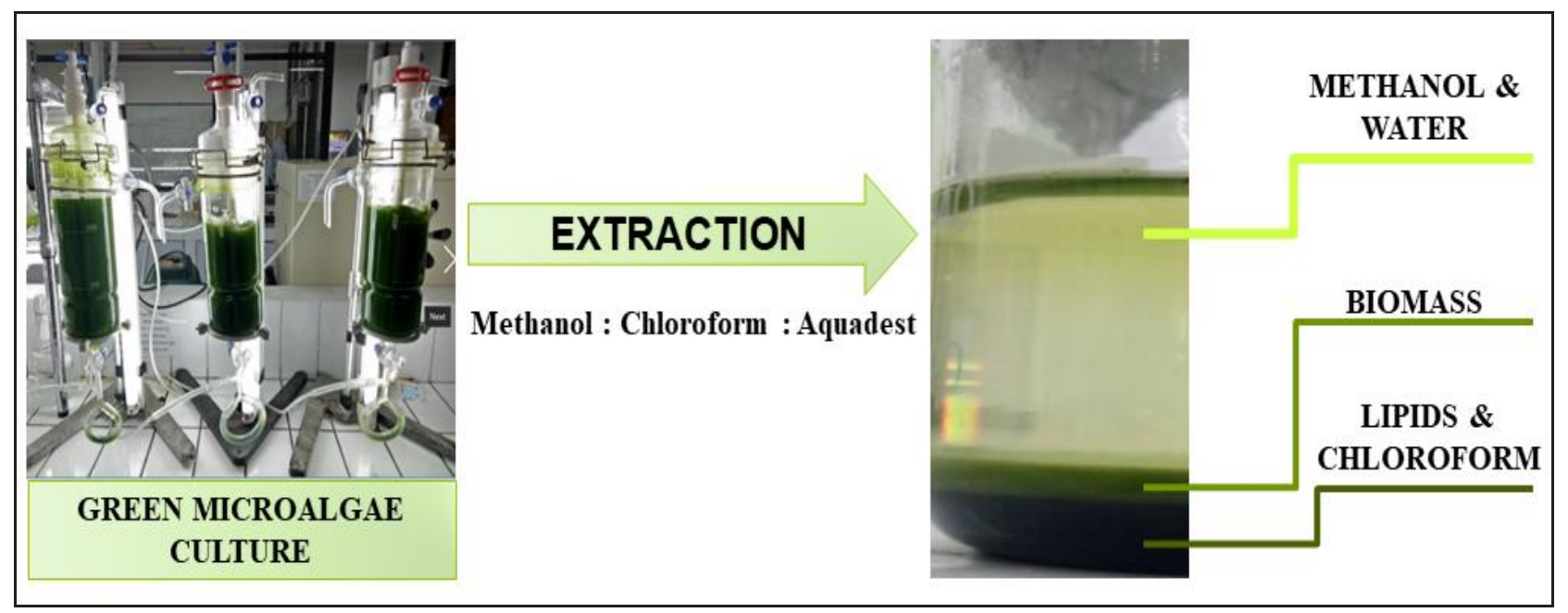

Fig. 2. Extraction of green microalgae. 
Table 1. Effect of amount of urea fertilizer to lipid contents.

\begin{tabular}{|c|c|c|c|c|c|c|c|c|}
\hline \multirow{2}{*}{$\begin{array}{c}\text { Amount of } \\
\text { Urea (gr) }\end{array}$} & \multicolumn{4}{|c|}{ Dry Weight (\% w/w) } & \multicolumn{4}{c|}{ Lipid Contents (\% w/w) } \\
\cline { 2 - 9 } & $\mathbf{R 1}$ & $\mathbf{R} 2$ & $\mathbf{R 3}$ & $\mathbf{R x}$ & $\mathbf{R} 1$ & $\mathbf{R 2}$ & $\mathbf{R 3}$ & $\mathbf{R x}$ \\
\hline 0.00 & $\mathbf{0 . 0 5}$ & $\mathbf{0 . 1 6}$ & $\mathbf{0 . 0 8}$ & $\mathbf{0 . 1 0}$ & $\mathbf{3 0 . 3 3}$ & $\mathbf{2 1 . 9 7}$ & $\mathbf{3 7 . 7 3}$ & $\mathbf{3 0 . 0 1}$ \\
\hline 0.50 & $\mathbf{0 . 1 8}$ & $\mathbf{0 . 2 5}$ & $\mathbf{0 . 3 4}$ & $\mathbf{0 . 2 6}$ & $\mathbf{3 3 . 9 7}$ & 43.24 & $\mathbf{3 1 . 8 5}$ & $\mathbf{3 6 . 3 5}$ \\
\hline 1.00 & $\mathbf{0 . 2 6}$ & $\mathbf{0 . 6 3}$ & $\mathbf{0 . 2 3}$ & $\mathbf{0 . 3 7}$ & $\mathbf{2 1 . 3 8}$ & $\mathbf{2 3 . 8 0}$ & $\mathbf{2 4 . 2 7}$ & $\mathbf{2 3 . 1 5}$ \\
\hline
\end{tabular}

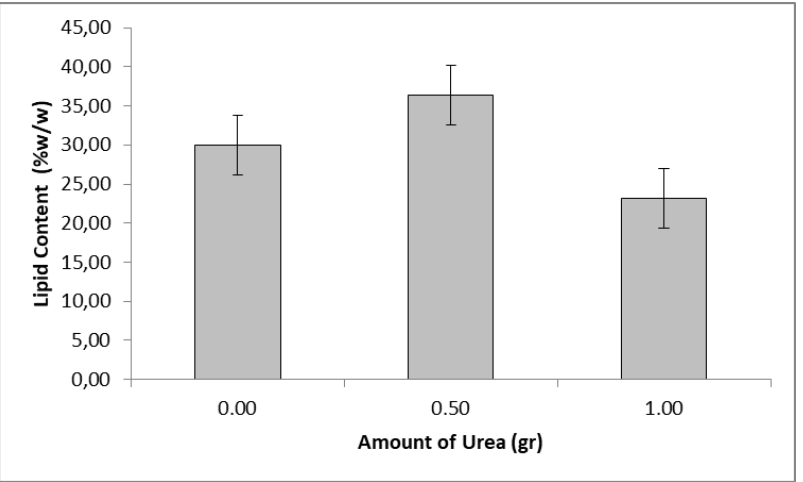

Fig. 3. Lipids content at different urea fertilizer addition.

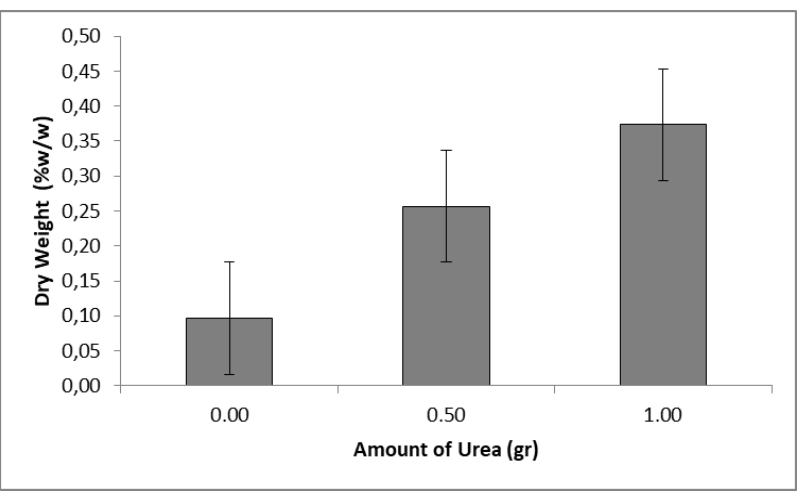

Fig. 4. Dry weight at different urea fertilizer addition.

Analysis of lipids and dry weight done in exponential phase because in this phase, microalgae is experiencing growth actively so it is expected to produce lipids and biomass in high quantities.

Lipids and biomass of microalgae obtained from extraction using an alcohol solvent, such as methanol and a non polar solvent in the form of chloroform. According to density of each type of solvent, it will produce multiple layers, as in Fig 2.

The results of extraction are separated to be followed by analysis of lipids content and dry weight to obtain the results of such research as in Table 1. Based on Fig 3., the highest lipids content $(36.35 \% \mathrm{w} / \mathrm{w})$ occurred in consortium of green microalgaes with the addition of urea fertilizer of 0.5 grams $(50 \%)$. The result of this research is also similar to another research about the variation of nutrients to one or two cultures of microalgae [10-15] that the addition of nitrogen source by only $50 \%$ (deficiency) could produce higher lipids content, but the amount of dry weight produced is less than the addition of $0.1 \mathrm{gr}$ (original) of urea fertilizer that is $0.37 \% \mathrm{w} / \mathrm{w}$ (Fig 4$)$.

\section{Conclusion}

The highest lipids content occurred in the condition of the urea fertilizer addition by $50 \%$ of original requirement. Thus, to obtain optimum high lipids content as biofuels, it needs to be conditioned microalgae under stress conditions, such as the existence of nitrogen source in growth medium up to $50 \%$ of original requirement.

\section{References}

1. Saito, S., Role of nuclear energy to a future society of shortage of energy resources ang global warming. Journal of Nuclear Materials. 398: 1-9, (2010)

2. Kumar, Parveen, et al., Extraction and Profilling of Lipids of Isolated Strain Chlorella fw-12 by GC$M S$. International Journal of Current Microbiology and Applied Sciences. 6(5): 1801-1810, (2017)

3. Zhu, Liandong, Sustainable Biodiesel Production from Microalgae Cultivated with Piggery Wastewater. University of Vaasa, (2014).

4. Griffiths, M. et al. Optimising Algal Lipid Productivity for Biodiesel Production. Bioprocess Engineering Research Unit, University of Capetown; 11th International Conference on Applied Phycology. Galway : Journal of Applied Phycology, (2008)

5. Mata TM, Martins AA, Caetano NS., Microalgae for biodiesel production and other applications: A review, Renewable and Sustainable Energy Reviews, 14:217-232, (2010).

6. Um B-H, Kim Y-S, Review: A Chance for Korea to Advance Algal-Biodiesel Technology, Journal of Industrial and Engineering Chemistry, 15: 1-7, (2008)

7. Sheehan, J., Dnahay, T., Benemann, J., and Roessler, P., A Look Back at The US Departement of Energy's Aquatic Species Program - Biodiesel from Algae. US DEO of Fuels Development, (1998)

8. Provasoli L. and Pintner I.J. Ecological implication of in vivo nutritional requirements of algae Flagellate. Ann NY Acad Sci. 56: 839. (1953).

9. Bligh, E.G. and Dyer, W.J., A Rapid Method of Total Lipid Extraction and Purification. Canadian Journal of Biochemistry and Physiology. 37: 8, (1959) 